\title{
Methicillin Resistance, Biofilm Formation and Resistance to Benzalkonium Chloride in Staphylococcus aureus Clinical Isolates
}

Carla Raggi, Perla Filippini, Monica Monaco, Annalisa Pantosti, Roberta Creti, and Lucilla Baldassarri

Dipartimento di Malattie Infettive, Parassitarie ed Immunomediate, Istituto Superiore di Sanita, Rome, Italy

\begin{abstract}
Purpose: To examine the resistance to benzalkonium chloride (BKC) and the distribution of biocide-resistance genes in S.aureus clinical isolates and to determine whether any correlation may exist with antibiotic resistance pattern and biofilm formation

Methods: MICs to BKC were determined in a collection of S.aureus (HA-MRSA, CA-MRSA and MSSA) both in suspension and on biofilm-embedded cells. Characteristic of the isolates (qac genes and biofilm formation) were determined by PCR and a plate assay, respectively.

Results: MICs to BKC were higher among MRSA than MSSA, where the CA-MRSA showed MIC levels closer to the MSSA group. qacA/B genes were found only among HA-MRSA and conferred higher resistance to the disinfectant while smr gene did not. MBC, but not MIC, were higher for biofilm embedded vs. planktonic cells, but no correlation was found with the ability to form biofilm.

Conclusion: We confirmed that presence of qacA/B but not smr confers higher resistance to BKC; MICs among MRSA were more spread compared to MSSA, suggesting that factors associated to the MR phenotype may confer resistance to $\mathrm{BKC}$. Interestingly, MSSA showed higher biocide tolerance in both the planktonic and biofilm form according to the MIC/MBC fold change values. Although no correlation could be observed between biofilm thickness and biocide resistance, biofilm-embedded cells responded differently to disinfectants suggesting the current practices for efficacy testing of biocides may not be relevant in the evaluation of disinfectant efficacy against biofilm-embedded microorganisms.
\end{abstract}

Keywords: S.aureus; Disinfectants; Biofilm; Antibiotic resistance

Abbreviations: BKC: Benzalkonium chloride; HA-MRSA: Hospital acquired-methicillin resistant Staphylococcus aureus; CA-MRSA: Community acquired-methicillin resistant Staphylococcus aureus; MSSA: Methicillin susceptible; Staphylococcus aureus; MIC: Minimal inhibitory concentration; MBC: Minimal bactericidal concentration

\section{Introduction}

Methicillin-resistant Staphylococcus aureus (MRSA) is a major nosocomial pathogen which includes, among its many virulence factors, the ability to produce biofilm. Such ability allows S.aureus to persistently colonize mucosal and inanimate surfaces alike, thus making its eradication from hospital settings very difficult.

One of the many characteristics of the biofilm-associated bacteria in clinical medicine is the markedly enhanced resistance to antimicrobial agents, sometimes leading to multidrug resistance and therapeutic failure $[1,2]$.

Although the mechanisms are poorly understood, there is evidence that biofilm-associated resistance may be related to modified nutrient environments, leading to suppression of growth rate within the biofilm, interaction between exopolymer matrices and the antimicrobial, as well as the development of biofilm-specific phenotypes [3]. In comparative antimicrobial susceptibility studies, many common gram-negative and gram-positive bacterial pathogens that produce biofilms show significantly higher antibiotic resistance rates than in their planktonic state $[4,5]$ but also higher resistance to disinfectants [6-8]. Correct practice of disinfectant use within hospitals, including hand hygiene, has long been considered the most appropriate first line of defence to limit infection outbreaks and to minimize antibiotic prescription [911]. However, some investigations have raised concern by suggesting that disinfectant overuse may induce mutations in microorganisms circulating in hospital settings and that cross-resistance between disinfectant and antibiotics may occur $[12,13]$. Bacteria, and in particular S. aureus, can acquire plasmid-encoded or mobile elementlocated multidrug resistance genes that negate bactericidal properties of a number of antimicrobial agents. It is known that some quaternary ammonium compounds (QACs) are subject to resistance mediated by efflux pumps coded by genes such as qacA and qacB [14] smr [15] and norA [16]. MRSA with decreased susceptibility to disinfectants has been isolated from clinical samples and settings $[17,18]$. It should be noted that, while the minimum inhibitory concentration (MIC) of disinfectants can and is determined in the same way as for antibiotics, the in-use concentrations of a disinfectant is never chosen on the basis of MIC because, unlike antibiotics, the purpose is to kill bacteria swiftly, in a matter of minutes. As elegantly stated by Cerf and colleagues [19] "the concept of resistance to antibiotics has many facets; however, they all lead to a "yes or no" situation where a bacterial strain or species or a fraction of a population "resists or does not resist". On the contrary, bacterial strains or species are "more resistant or less resistant" than others to a given disinfectant". With this in mind, it is difficult to clearly evaluate the antiseptic resistance of a given species because the difference

*Corresponding author: Lucilla Baldassarri, Dipartimento di Malattie Infettive, Parassitarie ed Immunomediate, Istituto Superiore di Sanità, Rome, Italy, Tel: +39.06.4990.2333; E-mail: lucilla.baldassarri@iss.it

Received June 17, 2013; Accepted July 12, 2013; Published July 15, 2013

Citation: Raggi C, Filippini P, Monaco M, Pantosti A, Creti R, et al, (2013) Methicillin Resistance, Biofilm Formation and Resistance to Benzalkonium Chloride in Staphylococcus aureus Clinical Isolates. Clin Microbial 2: 121. doi:10.4172/23275073.1000121

Copyright: ( 2013 Raggi C, et al. This is an open-access article distributed under the terms of the Creative Commons Attribution License, which permits unrestricted use, distribution, and reproduction in any medium, provided the original author and source are credited. 
between a resistant and a susceptible strain is usually small, and the MIC of antiseptic agents for antiseptic-resistant strains is lower than the user concentration of the agents. Nonetheless, an MRSA strain with decreased susceptibility to antiseptic agents mediated by an antisepticresistance gene is interpreted as an antiseptic-resistant strain [20].

Staphylococcal strains harboring plasmid-encoded genes, conferring increased resistance to antiseptics, have been demonstrated in clinical isolates of MRSA from Japan (32.6\%), Europe (63\%), and China (62\%) [21-23]. A study by Sidhu and colleagues [24] suggested that these genes may be increasing in MRSA strains, as the percentage of antiseptic resistance genes in MRSA isolated in Norway increased from none in 1990 , to $26.7 \%$ by 1995 , to $33.3 \%$ by 2005 .

Epidemiological information on antiseptic susceptibility and the distribution of resistance genes can be useful for nosocomial infection control. Although multidrug-efflux proteins have been studied extensively and have emerged as a major medical problem $[25,26]$, there is little information about antiseptic-resistant MRSA [17,27,28].

Cheeseman et al. [29,30] showed that genotypically distinct methicillin-resistant and -susceptible isolates of Staphylococcus aureus had different susceptibility to alcohol hand rubs. However, in these studies the mechanisms of resistance have not been identified; thus other factors might be involved in the different response to disinfecting agents. Activity of disinfectants is tested according to norms issued by the European Community through the European Committee for Standardization (Comité Européen de Normalisation, CEN). These norms establish that a substance can claim a disinfectant ability if it possesses determinate requirements, i.e. the ability to decrease the bacterial titre in suspension and in surface test of 4 and $5 \log _{10}$ reduction, respectively. All such tests are performed either on planktonic cells or on cells deposited on a carrier. No norm is currently available for testing the efficacy of any given substance on biofilm-embedded cells, where the disinfectant efficacy may be altered by the low penetration power, by the different metabolic state of cells in the lower biofilm layers, by inactivation due to the interaction with the extracellular matrix, etc. Thus, current testing practices contributes little indication to the correct use of disinfectants. Purpose of this study was, first, to examine the MICs to a commonly used quaternary ammonium compound (benzalkonium chloride) and the distribution of biocide-resistance genes in a small collection of S.aureus clinical isolates and then to determine whether any correlation exists between antibiotic resistance pattern, biofilm formation and biocide resistance.

\section{Materials and Methods}

\section{Bacterial strains}

A collection of 53 clinical S.aureus, including 17 hospital-associated (HA)-MRSA, 9 community-associated (CA)- MRSA, identified as described previously [31], and 27 methicillin-susceptible $S$. aureus (MSSA) available in our lab was utilised to test their susceptibility to benzalkonium chloride. Strains were from sepsis (MSSA and HAMRSA) or from skin and soft tissue infection or necrotising pneumonia (CA-MRSA). All strains had already been characterised for antibiotic resistance, presence of PVL genes and spa type [31,32].

S.aureus ATCC (American Type Culture Collection) 6538, the reference strain used in EN norms for biocidal efficacy testing, was utilised as standard.

\section{Media and chemicals}

Strains were stored in medium supplemented with $10 \%$ glycerol at $-80^{\circ} \mathrm{C}$. For retrieval and experiments, $5 \%$ Columbia-sheep blood agar and Muller Hinton Broth (Oxoid) were used. Benzalkonium chloride, sodium dodecylsulphate NLS90, polysorbate 80 and lecithin were purchased from Sigma-Aldrich.

\section{Susceptibility tests}

Minimal inhibitory concentration (MIC) and Minimal Bactericidal Concentration (MBC) were assayed using the two-fold broth dilution method according to European Committee on Antimicrobial Susceptibility Testing (EUCAST) guidelines by using a 96-well microtiter plate [33], with a few modifications. In short, serial 2-fold dilution of benzalkonium chloride (BKC) in Mueller-Hinton broth were prepared in 96 well microtiter plates and inoculated with $5 \times 10^{4}$ bacteria from fresh cultures (final volume in each well $200 \mu \mathrm{l}$ ). After $18 \mathrm{hrs}$ at $37^{\circ} \mathrm{C}$, the lowest concentration of the biocide inhibiting visible growth was recorded as MIC. To disrupt any residual activity of the disinfectant, $20 \mu \mathrm{l}$ neutralizer (stock solution $5 \mathrm{~g} / \mathrm{L}$ sodium dodecylsulphate +30 $\mathrm{g} / \mathrm{L}$ polysorbate 80 and $3 \mathrm{~g} / \mathrm{L}$ lecithin, as described in EN norms for neutralization of quaternary ammonium compounds) were added to each well. After neutralization, MBC (i.e. the concentration that produced $\geq 99.9 \%$ killing of cells) was determined by plating $100 \mu \mathrm{L}$ aliquots on Mueller-Hinton agar plates, which were incubated for further $18 \mathrm{hrs}$ at $37^{\circ} \mathrm{C}$ in $5 \% \mathrm{CO}_{2}$ atmosphere and colonies were counted. Controls to evaluate any effect of the neutralizer on cell viability were included in each run.

To determine the MIC/MBC on biofilm embedded cells, a test was set up where the inoculum (i.e. the pre-formed biofilm) was standardized through a careful measurement of incubation time, preinoculum, and washing steps. Biofilm was allowed to form on the bottom of 96 well plates for 18 hours. Serial two-fold biocide dilution was then added to each well and plates were further incubated for 24 hrs at $37^{\circ} \mathrm{C}$ in $5 \% \mathrm{CO}_{2}$ atmosphere. MIC was defined as the lowest concentration of biocide inhibiting visible growth as determined by $\mathrm{OD}_{600 \mathrm{~nm}}$ measurement. To determine the $\mathrm{MBC}$ while avoiding the necessity to scrape cells from the well's bottom, we evaluated the bacterial viability by using the metabolic conversion of a formazan dye (XTT). A working solution containing XTT and menadione (both from Sigma Chemical Co., St Louis, MO, USA) was prepared by adding 50 $\mathrm{mL}$ of XTT from $1 \mathrm{mg} / \mathrm{mL}$ XTT stock and $4 \mathrm{~mL}$ of menadione from 1 $\mathrm{mM}$ menadione stock solution (diluted from $10 \mathrm{mM}$ menadione stock) to $4 \mathrm{~mL}$ of PBS and mixing gently. The XTT/menadione mixture was added to each well and microtitre plates were covered with aluminium foil and incubated for $120^{\prime}$ at $37^{\circ} \mathrm{C}$. In addition, the optical density at $490 \mathrm{~nm}$ was read using a microplate reader. A standard growth curve (correlation coefficient $\mathrm{R}^{2}=0.983$ ) to put in relation the XTT signal with bacterial cell titer was created and the OD signal corresponding to a 3 $\log _{10}$ reduction compared to the control was defined as the MBC.

\section{Biofilm Assay}

The ability to form biofilm was measured as described previously [2]. Briefly, isolates were allowed to form biofilm on the bottom of 96 well plates for $18 \mathrm{hrs}$ at $37^{\circ} \mathrm{C}$. Wells were then emptied, washed with saline solution, let dry in a $40^{\circ} \mathrm{C}$ heater, stained with crystal violet and OD recorded at $570 \mathrm{~nm}$ by an automatic spectrophotometer.

\section{Gene Pattern Characterization}

Polymerase chain reaction (PCR) for detection of $q a c A / B$ and $s m r$ genes was performed according to Noguchi et al. [17]. Briefly, singlecolony bacteria were transferred into $100 \mu \mathrm{l} \mathrm{H} \mathrm{H}_{2} \mathrm{O}$. Cells were suspended and $1 \mu \mathrm{l}$ of the cell suspension was added directly into $25 \mu \mathrm{l}$ of the PCR 
mixture containing either sets of primers and $12.5 \mu \mathrm{l}$ PCR master mix (Promega). PCR was performed using an initial denaturation step of $96^{\circ} \mathrm{C}$ for $3 \mathrm{~min}, 25 \mathrm{cycles}$ of $94^{\circ} \mathrm{C}$ for $20 \mathrm{~s}, 53^{\circ} \mathrm{C}$ for $20 \mathrm{~s}$ and $72^{\circ} \mathrm{C}$ for 20 s, and a final extension step at $72^{\circ} \mathrm{C}$ for $5 \mathrm{~min}$.

The following primers were used for the amplification of the $q a c A / B$ and $s m r$ genes. $q a c A / B$ : forward primer 5'-CTATGGCAATAGGAGATATGGTGT, reverse primer 5'-CCACTACAGATTCTTCAGCTACATG, size of the amplification product $321 \mathrm{bp}$; smr: forward primer 5'-AAACAATGCAACACCTACCACT, reverse primer 5'-AACGAAACTACGCCGACTATG, size of the amplification product $157 \mathrm{bp}$. PCR products were analysed by agarose gel electrophoresis.

\section{Statistical Analysis}

Differences of optical densities (ODs) of biofilm were analysed for significance by the Wilcoxon test for related rankable scores. All evaluations were done with the Statistica 4.1 software (StatSoft, USA) program on a McIntosh computer.

\section{Results}

A total of 53 strains from a collection of clinical isolates from different sources available in our Lab were examined. Isolates were obtained from hospitals distributed throughout Italy, collected between 2005 and 2009. Typing and molecular characteristics of these strains have already been published elsewhere [31,32]. To summarize, 14 and 20 spa type were identified among MRSA and MSSA, respectively. The 9 CA-MRSA isolates all carried the PVL genes.

Considering the collection on the whole, the majority of S.aureus isolates (29 out of 53) had a MIC to benzalkonium chloride of $2 \mathrm{mg} / \mathrm{L}$ (Table 1). When grouping MRSA and MSSA, almost the totality of MSSA (25/27) confirmed a MIC of $2 \mathrm{mg} / \mathrm{L}$, and only 2 isolates had an MIC of $4 \mathrm{mg} / \mathrm{L}$. The MIC of the methicillin-susceptible reference strain S.aureus ATCC 6538 was in line with the majority of MSSA isolates (2 $\mathrm{mg} / \mathrm{L}$ ). Concerning the MRSA group, the majority $(57,7 \%)$ had an MIC of $4 \mathrm{mg} / \mathrm{L}$. There was also a small cluster with a MIC of $16 \mathrm{mg} / \mathrm{L}$ and, in general, MICs distribution among MRSA was more spread compared to the MSSA group (Table 1). Of the 4 strains with the higher MICs, three were spa type t041 and one was t5831. MIC of 8 out of 9 CAMRSA isolates fell in the lower range of MICs $(4 \mathrm{mg} / \mathrm{L}$; one isolate had a MIC of $8 \mathrm{mg} / \mathrm{L}$ ).

Molecular amplification detected the $q a c A / B$ gene in 4 strains $(7,5 \%)$ whereas the $s m r$ gene was detected in 2 strains $(3,7 \%)$. No isolates contained both genes. The 4 qacA/B carrying strains were all MRSA, while the $s m r$ carrying strains were one MSSA and one MRSA. MIC values were significantly higher for strains harboring qacA/B (16 $\mathrm{mg} / \mathrm{L}$ ), but not $s m r$, vs. strains negative for either of these genes.

Biofilm formation was, as expected, quite a common feature in the collection examined, with a large range of ODs observed (Figure 1a); MRSA formed significantly more biofilm compared to MSSA (median 0,753 vs. 0,433 , respectively, $P<0.002$ ). Growth in the presence of subMIC BKC concentration (the highest biocide concentration allowing bacterial growth, i.e. one dilution after the MIC) either slightly inhibited, or had no effect, on biofilm formation (Figure 1b).

\begin{tabular}{|l|c|c|c|c|c|}
\hline \multirow{2}{*}{ S.aureus } & \multicolumn{4}{|c|}{ MIC (no. of strains) (\%) } & \multirow{2}{*}{$\begin{array}{c}\text { Total no. of } \\
\text { strains }\end{array}$} \\
\cline { 2 - 5 } & $2 \mathrm{mg} / \mathrm{L}$ & $4 \mathrm{mg} / \mathrm{L}$ & $8 \mathrm{mg} / \mathrm{L}$ & $16 \mathrm{mg} / \mathrm{L}$ & 26 \\
\hline MRSA & $4(15,4)$ & $14(53,8)$ & $4(15,4)$ & $4(15,4)$ & 26 \\
\hline MSSA & $25(92,6)$ & $2(7,4)$ & - & - & 27 \\
\hline
\end{tabular}

Table 1: MICs values distribution among MRSA and MSSA strains examined in this study.

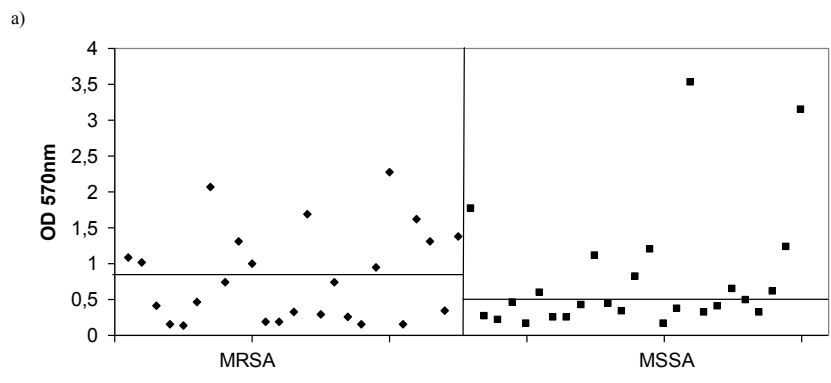

b)

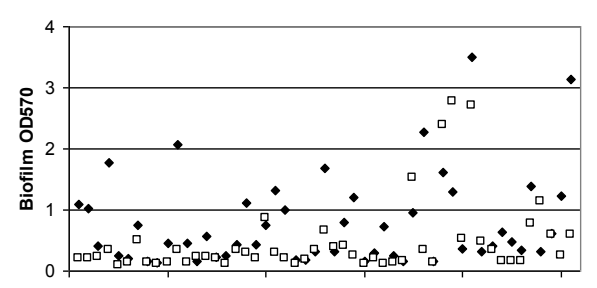

Figure 1: a) ODs of biofilm formed by MR or MS S.aureus (line marks the median OD in the two groups). b) ODs of biofilm formed by each strain in plain medium (full diamonds) or in medium containing subMIC concentration of benzalkonium chloride (empty squares); in the latter condition, biofilm OD was always lower compared to that recorded after growth in plain medium.

\begin{tabular}{|c|c|c|c|c|c|c|c|c|c|c|}
\hline \multirow[t]{2}{*}{ Strain } & \multirow[t]{2}{*}{ spa type } & \multirow[t]{2}{*}{ qacAB } & \multirow[t]{2}{*}{$s m r$} & \multirow[t]{2}{*}{ Biofilm OD } & \multicolumn{2}{|c|}{ MIC } & \multirow{2}{*}{\begin{tabular}{|c|} 
MBC \\
$\mathrm{P}$ \\
\end{tabular}} & \multicolumn{3}{|c|}{$\begin{array}{l}\text { Fold change } \\
\text { (MIC/MBC) }\end{array}$} \\
\hline & & & & & $\mathrm{P}$ & $B$ & & B & $P$ & B \\
\hline \multicolumn{11}{|l|}{ MRSA } \\
\hline SA 400 & t041 & + & - & 1.004 & 16 & 16 & 16 & 80 & 1 & 5 \\
\hline SA 109 & t041 & + & - & 2.072 & 16 & 16 & 32 & 80 & 2 & 5 \\
\hline SA $24^{a}$ & $\mathrm{t} 755$ & - & - & 2.281 & 4 & 16 & 8 & 40 & 2 & 2,5 \\
\hline SA 548 & t008 & - & - & 1.304 & 4 & 4 & 4 & 40 & 1 & 10 \\
\hline SA 691 & t041 & + & - & 0.946 & 16 & 16 & 16 & 80 & 1 & 5 \\
\hline SA 172 & t032 & - & - & 1.620 & 4 & 4 & 8 & 80 & 2 & 20 \\
\hline SA 22a & $\mathrm{t} 319$ & - & + & 0.980 & 4 & 8 & 4 & 40 & 1 & 5 \\
\hline SA 630 & t5831 & + & - & 0.733 & 16 & 16 & 16 & 80 & 1 & 5 \\
\hline \multicolumn{11}{|l|}{ MSSA } \\
\hline SA 92 & t091 & - & - & 0.454 & 2 & 4 & 8 & 40 & 4 & 10 \\
\hline SA 160 & t078 & - & - & 3.143 & 2 & 4 & 8 & 80 & 4 & 20 \\
\hline SA 162 & t002 & - & - & 3.509 & 2 & 4 & 8 & 40 & 4 & 10 \\
\hline SA 227 & t031 & - & - & 0.150 & 2 & 2 & 8 & 40 & 4 & 20 \\
\hline SA 261 & t091 & - & - & 0.435 & 2 & 2 & 8 & 40 & 4 & 20 \\
\hline SA 366 & t012 & - & - & 0.433 & 4 & 4 & 8 & 40 & 2 & 10 \\
\hline SA 429 & t005 & - & - & 0.633 & 2 & 8 & 8 & 40 & 4 & 5 \\
\hline SA 184 & $\mathrm{t} 442$ & - & + & 1.450 & 2 & 2 & 8 & 40 & 4 & 20 \\
\hline SA 6538 & $\operatorname{Ref}^{*}$ & - & - & 0.422 & 4 & 4 & 8 & 40 & 2 & 10 \\
\hline
\end{tabular}

${ }^{a}$ Community acquired (CA)-MRSA; *reference strain

Table 2: MICs and MBCs values of planktonic-(P) or biofilm (B)-embedded cells in a selection of MSSA and MRSA isolates, in relation to the ability to form biofilm and to the presence of biocide-resistance determinants.

MIC was also determined on biofilm embedded cells in some selected isolates. Selection included all the $q a c \mathrm{~A} / \mathrm{B}$ and $s m r$ positive strains, plus a comparable number of high and low biofilm producers, to evaluate whether genes and/or biofilm thickness had any effect in the behavior of biofilm-embedded- vs. planktonic cells. MIC values for planktonic vs sessile cells are shown in Table 2. Eleven out of the 17 strains tested showed the same MIC value in both forms while 4 additional strains showed a doubling of the minimal biocide concentration required to 
inhibit biofilm-embedded cells vs. the planktonic ones. This one-fold shift remains within the deviation from the mean MIC as measured in repeated experiments (not shown). More interesting was the 4-fold increase in the MIC value observed for one of the two CA-MRSA (SA 24) examined and for one MSSA isolate (SA 184), which exhibited a 3 -fold increase. However, as more robust indicators of cell tolerance, the evaluation of the fold change (MIC/MBC) highlighted an interesting feature of MSSA isolates that exhibited a mean higher fold change, both in planktonic and biofilm form (Table 2).

In any case, no correlation could be found with either higher MIC, $\mathrm{MBC}$ or fold change and biofilm thickness or the presence of resistance genes (Table 2).

\section{Discussion}

MRSA is one of the major nosocomial pathogen which has been shown to be resistant not only to antibiotics but also to several disinfectants $[17,18]$; this may render the use of disinfectants useless and impair one of the most popular practice to curb infections in nosocomial settings in an attempt to prevent antibiotics overuse $[10,11]$. Information on the local situation on antiseptic susceptibility and distribution of resistance genes would be useful for nosocomial infection control, especially as far as MRSA are concerned [17,27,28].

Besides the intrinsic or acquired resistance to antimicrobials, S.aureus is able to produce biofilm on both mucosal and inanimate surfaces, making its eradication even more difficult. For these reasons, purpose of our study was, first, to attain a deeper knowledge of the epidemiological situation on antiseptic susceptibility and distribution of resistance determinants in a small collection of S.aureus from Italian hospitals in comparison to published data. Further, we wished to evaluate the possible influence of biofilm, if any, on the ability of S.aureus to resist disinfection.

MICs values appeared to be more spread among MRSA than MSSA isolates, suggesting a different distribution of genetic determinants for biocide resistance between these two groups. A European survey by Mayer et al. [28] reported the qacA/B genes in $63 \%$ of MRSA vs $12 \%$ of MSSA isolates, while $s m r$ gene was found in $6.4 \%$ and $5 \%$ of MRSA and MSSA isolates, respectively. The Authors hypothesised that the rather high prevalence of $q a c A / B$ genes might be due to the selective pressure imposed by disinfecting agents (e.g. acriflavine, cetyltrimethylammonium bromide and benzalkonium chloride) used in hospitals.

We could confirm the larger prevalence of $q a c \mathrm{~A} / \mathrm{B}$ genes among MRSA (15.4\%) vs. MSSA (0\%); the percentage of such genes-carrying isolates in our collection as a whole was not so high, although it increases if we consider only HA-MRSA isolates $(23,5 \%)$, as none of the CA- MRSA carried the qac genes. Still, frequency of such genes does not reach the astounding percentage reported by Mayer et al. [28] possibly due to local policies of disinfectant utilization or local circulation of particular clones. Our percentages were closer to those of a Canadian study were only $2 \%$ of 334 MRSA isolates were qacA/B positive [34]. Also in this case Authors commented upon the fact that local utilization of disinfectants may affect the distribution of resistance genes. Unfortunately, as also pointed out in a recent document by the $\mathrm{EU}$ [35], it is very difficult to assess/quantify the exposure of bacteria to biocides and/or to their metabolites in various matrices due to the lack of information on production and use volumes. Still, this remain a very important aspect as the concentrations detected in some environmental locations are high enough to select for bacterial strains exhibiting a decreased susceptibility against antibacterial compounds or to trigger the expression of associated resistance mechanisms in vitro [36-38]. The prevalence of $q a c A / B$ genes among MRSA compared to MSSA is not surprising as such genes may co-localize on multi-resistant plasmids such as pSK1 or mobile elements such as the staphylococcal chromosome cassette mec, that frequently carries a number of different resistance determinants, including heavy metal resistance, besides methicillin resistance $[39,40]$.

The presence of $q a c A / B$ genes, but not $s m r$, correlated with a significantly higher MIC to benzalkonium chloride, but also methicillin resistance appeared to correlate with a decreased susceptibility profile, possibly indicating the existence of a partial resistance to benzalkonium chloride mediated by genes other than $q a c A / B$. As a matter of fact also genes such as nor A, norC, mepA, mdeA [41-43], other genes of the QAC family, or other as yet unidentified MDR pump genes may contribute to the extrusion of biocides, limiting their disinfectant action.

Three of the four isolates here described, that showed higher MICs to benzalkonium chloride, belonged to spa type t041. t041 is the most common MRSA spa type isolated from Italian hospitals and it is associated to characteristics of reduced susceptibility to vancomycin including strains with intermediate resistance to vancomycin (VISA) and strains containing heteroresistant subpopulation (h-VISA) in high percentage (14\%) [32].In a large European study, t041 is defined as the Northern Balkan/Adriatic cluster, since it was found in Northern and Central Italy and in other countries such as Austria, Hungary, Slovenia and Croatia [44]. Increasing resistance to antibiotic, including vancomycin, combined to resistance to disinfectants could limit t041 hospital eradication and favorable outcome of patients.

An attempt was made to evaluate if any correlation could be found between the ability to form biofilm and resistance to biocides. Small differences were found, with only two isolates showing a three-fold and a four-fold increase in MIC of planktonic vs. biofilm-embedded cells, respectively. On the other hand, MBCs values were higher for biofilm embedded cells compared to planktonic ones, however no correlation could be observed with the biofilm thickness as evaluated through measuring of the optical densities. Even the three t041-agr group II isolates carrying the $q a c \mathrm{~A} / \mathrm{B}$ gene and showing the highest MIC when tested in its planktonic state, did not differ from strains with different characteristics when resistance of biofilm-embedded cells was evaluated. This would suggest that the higher concentrations of the biocide needed to kill biofilm-embedded cells may rather be due to a different metabolic state of sessile cells than to the presence of resistance determinants. Moretro et al. [8] also observed that the efficacy of some disinfectants varied considerably in their activity against suspended Salmonella cells compared to attached ones, either to those embedded in a pellicle or in a biofilm, although possible mechanisms were not discussed.

More interesting was the information provided by the fold change (MIC/MBC) of the strains examined. The methicillin-susceptible group showed a mean fold change significantly higher than the MRSA group, for both planktonic and biofilm-embedded cells. Fold change is a robust indicator of bacterial tolerance; as it is, it was expected that biofilmembedded cells would show a higher fold change. Less expected was the difference between MSSA and MRSA, although this could be ascribed to the fact that MRSA group had higher MBC in planktonic mode. Nevertheless, it had been suggested [2] that microorganisms lacking genetic determinants for resistance may use other, as yet undefined, mechanism(s) as survival tools to increase their fitness Biofilm does not appear to be one of those, in this case, as no correlation could be observed between biofilm thickness and biocide resistance. Still, 
Citation: Raggi C, Filippini P, Monaco M, Pantosti A, Creti R, et al, (2013) Methicillin Resistance, Biofilm Formation and Resistance to Benzalkonium Chloride in Staphylococcus aureus Clinical Isolates. Clin Microbial 2: 121. doi:10.4172/2327-5073.1000121

Page 5 of 6

biofilm-embedded cells respond differently to disinfectants, as they do to other antimicrobials, suggesting that testing of biocides either in suspension or on surface assays as indicated by the EU norms, might not be relevant in the evaluation of disinfectant efficacy against biofilmembedded microorganisms. This despite the fact that the observed MBCs were still lower than the concentration suggested for use of benzalkonium chloride for disinfection $(1 \% \mathrm{w} / \mathrm{v})$.

We could confirm that the presence of $q a c \mathrm{~A} / \mathrm{B}$ but not $s m r$ confers higher resistance to benzalkonium chloride. However, MICs among MRSA were more spread compared to MSSA, possibly indicating that factors associated to the MR phenotype may confer resistance to BKC, even though tolerance appeared to be higher for MSSA isolates.

In any case, diffusion of specific genes for biocide resistance do not appear to be so widespread in our collection; if this depends on a more restricted use of disinfectants in Italian hospitals or if other factors are involved should be further investigated.

We believe that progresses in the study of the effect of disinfectants on pathogens would come from being able to quantify the amount of disinfectants used per area, so to evaluate the real impact of the use of such substances on the lateral transfer of resistance determinants between microorganisms and/or on the emergence of mutations conferring higher resistance to biocides.

\section{Acknowledgements}

We wish to thank Monica Imperi and Marco Pataracchia for technical assistance, Anna Maria Marella for secretarial help, and Graziella Orefici and Marco Oggioni for useful discussion.

\section{Funding}

This work was partially supported by the European Community's Seventh Framework Programme (FP-7 2007/2013) under grant agreement n. KBBE 227258 (BIOHYPO) to LB.

\section{Transparency declaration}

The Authors declares that no conflict of interest existed in relation to what reported in this manuscript.

\section{References}

1. Hall-Stoodley L, Stoodley P (2009) Evolving concepts in biofilm infections. Cell Microbiol 11: 1034-1043.

2. Baldassarri L, Creti R, Recchia S, Imperi M, Facinelli B, et al. (2006) Therapeutic failures of antibiotics used to treat macrolide-susceptible Streptococcus pyogenes infections may be due to biofilm formation. J Clin Microbiol 44: 2721 2727.

3. Mah TF, O'Toole GA (2001) Mechanisms of biofilm resistance to antimicrobial agents. Trends Microbiol 9: 34-39.

4. Olson ME, Ceri H, Morck DW, Buret AG, Read RR (2002) Biofilm bacteria: formation and comparative susceptibility to antibiotics. Can J Vet Res 66: 8692.

5. Papavasileiou K, Papavasileiou E, Tseleni-Kotsovili A, Bersimis S, Nicolaou et al. (2010) Comparative antimicrobial susceptibility of biofilm versus planktonic forms of Salmonella enterica strains isolated from children with gastroenteritis. Eur J Clin Microbiol Infect Dis 29: 1401-1405.

6. Costerton JW, Stewart PS (2001) Battling biofilms. Sci Am 285: 74-81.

7. Scher K, Romling U, Yaron S (2005) Effect of heat, acidification, and chlorination on Salmonella enterica serovar typhimurium cells in a biofilm formed at the airliquid interface. Appl Environ Microbiol 71: 1163-1168.

8. Møretrø T, Vestby LK, Nesse LL, Storheim SE, Kotlarz K, et al. (2009) Evaluation of efficacy of disinfectants against Salmonella from the feed industry. J Appl Microbiol 106: 1005-1012.

9. Boyce JM, Pittet D (2002) Guideline for hand hygiene in healthcare settings. Recommendations of the Healthcare Infection Control Practices Advisory Committee and the HICPAC/SHEA/APIC/IDSA Hand Hygiene Task Force.
Society for Healthcare Epidemiology of America/Association for Professionals in Infection Control/Infectious Diseases Society of America. Morbid Mortal Wkly Rep Recomm Rep 51: 1-45.

10. Dettenkofer M, Wenzler S, Amthor S, Antes G, Motschall E, et al (2004) Does disinfection of environmental surfaces influence nosocomial infection rates? A systematic review. Am J Infect Control 32: 84-89.

11. Murtough SM, Hiom SJ, Palmer M, Russell AD (2001) Biocide rotation in the healthcare setting: is there a case for policy implementation? J Hosp Infect 48: $1-6$.

12. Brooks SE, Walczak MA, Hameed R, Coonan P (2002) Chlorhexidine resistance in antibiotic-resistant bacteria isolated from the surfaces of dispensers of soap containing chlorhexidine. Infect Control Hosp Epidemiol 23: 692-695.

13. Schweizer HP (2001) Triclosan: a widely used biocide and its link to antibiotics. FEMS Microbiol Lett 202: 1-7.

14. Paulsen IT, Brown MH, Littlejohn TG, Mitchell BA, Skurray RA (1996) Multidrug resistance proteins QacA and QacB from Staphylococcus aureus: membrane topology and identification of residues involved in substrate specificity. Proc Natl Acad Sci U S A 93: 3630-3635.

15. Grinius L, Dreguniene G, Goldberg EB, Liao CH, Projan SJ (1992) A staphylococcal multidrug resistance gene product is a member of a new protein family. Plasmid 27: 119-129.

16. Neyfakh AA, Borsch CM, Kaatz GW (1993) Fluoroquinolone resistance protein NorA of Staphylococcus aureus is a multidrug efflux transporter. Antimicrob Agents Chemother 37: 128-129.

17. Noguchi N, Hase M, Kitta M, Sasatsu M, Deguchi K, et al. (1999) Antiseptic susceptibility and distribution of antiseptic-resistance genes in methicillinresistant Staphylococcus aureus. FEMS Microbiol Lett 172: 247-253.

18. Suller MT, Russell AD (1999) Antibiotic and biocide resistance in methicillinresistant Staphylococcus aureus and vancomycin-resistant enterococcus. J Hosp Infect 43: 281-291.

19. Cerf O, Carpentier B, Sanders $P$ (2010) Tests for determining in-use concentrations of antibiotics and disinfectants are based on entirely different concepts: "resistance" has different meanings. Int J Food Microbiol 136: $247-$ 254.

20. Lyon BR, Skurray R (1987) Antimicrobial resistance of Staphylococcus aureus genetic basis. Microbiol Rev 51: 88-134.

21. Wang C, Cai P, Zhan Q, Mi Z, Huang Z, et al. (2008) Distribution of antiseptic-resistance genes qacA/B in clinical isolates of meticillin-resistant Staphylococcus aureus in China. J Hosp Infect 69: 393-394.

22. Wang JT, Sheng WH, Wang JL, Chen D, Chen ML, et al. (2008) Longitudina analysis of chlorhexidine susceptibilities of nosocomial methicillin-resistant Staphylococcus aureus isolates at a teaching hospital in Taiwan. J Antimicrob Chemother 62: 514-517.

23. Walsh SE, Maillard JY, Russell AD, Catrenich CE, Charbonneau DL, et al. (2003) Development of bacterial resistance to several biocides and effects on antibiotic susceptibility. J Hosp Infect 55: 98-107.

24. Sidhu MS, Heir E, Leegaard T, Wiger K, HolckA(2002) Frequency of disinfectant resistance genes and genetic linkage with beta-lactamase transposon Tn552 among clinical staphylococci. Antimicrob Agents Chemother 46: 2797-2803.

25. Putman M, van Veen HW, Konings WN (2000) Molecular properties of bacteria multidrug transporters. Microbiol Mol Biol Rev 64: 672-693.

26. Russell AD (2002) Mechanisms of antimicrobial action of antiseptics and disinfectants: an increasingly important area of investigation. J Antimicrob Chemother 49: 597-599.

27. Alam MM, Kobayashi N, Uehara N, Watanabe N (2003) Analysis on distribution and genomic diversity of high-level antiseptic resistance genes qacA and qacB in human clinical isolates of Staphylococcus aureus. Microb Drug Resist 9 : 109-121.

28. Mayer S, Boos M, Beyer A, Fluit AC, Schmitz FJ (2001) Distribution of the antiseptic resistance genes qacA, qacB and qacC in 497 methicillin-resistant and -susceptible European isolates of Staphylococcus aureus. J Antimicrob Chemother 47: 896-897.

29. Cheeseman KE, Denyer SP, Hosein IK, Williams GJ, Maillard JY (2009) Evaluation of the bactericidal efficacy of three different alcohol hand rubs against 57 clinical isolates of S. aureus. J Hosp Infect 72: 319-325. 
Citation: Raggi C, Filippini P, Monaco M, Pantosti A, Creti R, et al, (2013) Methicillin Resistance, Biofilm Formation and Resistance to Benzalkonium Chloride in Staphylococcus aureus Clinical Isolates. Clin Microbial 2: 121. doi:10.4172/2327-5073.1000121

30. Cheeseman KE, Denyer SP, Hosein IK, Williams GJ, Maillard JY (2011) Evaluation of the bactericidal efficacy of three different alcohol hand rubs against clinical isolates of Staphylococcus aureus using an ex vivo carrier test. J Hosp Infect 77: 21-24.

31. Sanchini A, Campanile F, Monaco M, Cafiso V, Rasigade JP, et al. (2011) DNA microarray-based characterisation of Panton-Valentine leucocidine-positive community-acquired methicillin- resistant Staphylococcus aureus from Italy. Eur J Clin Microbiol Infect Dis DOI: 10.1007/s10096-011-1234-x

32. Monaco M, Sanchini A, Grundmann H, Pantosti A; EARSS-Italy S aureus typing Group. (2010) Vancomycin-heteroresistant phenotype in invasive methicillinresistant Staphylococcus aureus isolates belonging to spa type 041. Eur J Clin Microbiol Infect Dis 29: 771-777.

33. Pereira V, Lopes C, Castro A, Silva J, Gibbs P, et al. (2009) Characterization for enterotoxin production, virulence factors, and antibiotic susceptibility of Staphylococcus aureus isolates from various foods in Portugal. Food Microbio 26: 278-282

34. Longtin J, Seah C, Siebert K, McGeer A, Simor A, et al. (2011) Distribution of antiseptic resistance genes qacA, qacB, and smr in methicillin-resistan Staphylococcus aureus isolated in Toronto, Canada, from 2005 to 2009. Antimicrob Agents Chemother 55: 2999-3001.

35. European Commission (2010) Research strategy to address the knowledge gaps on the antimicrobial resistance effects of biocides. Scientific Committee on Emerging and Newly Identified Health Risks. SCENHIR.

36. Kumar KS, Priya SM, Peck AM, Sajwan KS (2010) Mass loadings of triclosan and triclocarbon from four wastewater treatment plants to three rivers and landfill in Savannah, Georgia, USA. Arch Environ Contam Toxicol 58: $275-285$
37. Pedrouzo M, Borrull F, Marcé RM, Pocurull E (2009) Ultra-high-performance liquid chromatography-tandem mass spectrometry for determining the presence of eleven personal care products in surface and wastewaters. J Chromatogr A 1216: 6994-7000.

38. Wilson B, Chen RF, Cantwell M, Gontz A, Zhu J, et al. (2009) The partitioning of Triclosan between aqueous and particulate bound phases in the Hudson River Estuary. Mar Pollut Bull 59: 207-212.

39. Paulsen IT, Firth N, Skurray RA (1997) Resistance to antimicrobial agents other than ß-lactams. In Crossley K B, Archer G L, eds. The Staphylococci in Human Disease. New York, Churchill Livingston Inc, 175-212.

40. International Working Group on the Classification of Staphylococcal Cassette Chromosome Elements (IWG-SCC) (2009) Classification of staphylococcal cassette chromosome mec (SCCmec): guidelines for reporting novel SCCmec elements. Antimicrob Agents Chemother 53: 4961-4967.

41. Littlejohn TG, DiBerardino D, Messerotti LJ, Spiers SJ, Skurray RA (1991) Structure and evolution of a family of genes encoding antiseptic and disinfectan resistance in Staphylococcus aureus. Gene 101: 59-66.

42. Huang J, O'Toole PW, Shen W, Amrine-Madsen H, Jiang X, et al. (2004) Nove chromosomally encoded multidrug efflux transporter MdeA in Staphylococcus aureus. Antimicrob Agents Chemother 48: 909-917.

43. Huet AA, Raygada JL, Mendiratta K, Seo SM, Kaatz GW (2008) Multidrug efflux pump overexpression in Staphylococcus aureus after single and multiple in vitro exposures to biocides and dyes. Microbiology 154: 3144-3153.

44. Grundmann H, Aanensen DM, van den Wijngaard CC, Spratt BG, Harmsen D et al., (2010) European Staphylococcal Reference Laboratory Working Group. Geographic distribution of Staphylococcus aureus causing invasive infections in Europe: a molecular-epidemiological analysis. PLoS Med 7 (1): e1000215. 